PERSPECTIVE

\title{
Cervical Cancer Screening for Patients on the Female-to-Male Spectrum: a Narrative Review and Guide for Clinicians
}

\author{
Jennifer Potter, $M D^{1,2,3}$, Sarah M. Peitzmeier, $M S P H^{1,4}$, Ida Bernstein, BA ${ }^{2}$, Sari L. Reisner, ScD, MA ${ }^{1,5}$, \\ Natalie M. Alizaga, MPH, MPhil', Madina Agénor, SCD, MPH $H^{5,7}$, and Dana J. Pardee, $B S^{7}$ \\ 'The Fenway Institute, Fenway Health, Boston, MA, USA; ${ }^{2}$ Harvard Medical School, Boston, MA, USA; ${ }^{3}$ Beth Israel Deaconess Medical Center, Boston,
MA, USA; ${ }^{4}$ Department of Population, Family, and Reproductive Health, Johns Hopkins Bloomberg School of Public Health, Baltimore, MD, USA;
${ }^{5}$ Department of Social and Behavioral Sciences, Harvard T.H. Chan School of Public Health, Boston, MA, USA; ${ }^{6}$ Department of Psychology, The
George Washington University, Washington, DC, USA; ${ }^{7}$ Center for Community-Based Research, Dana-Farber Cancer Institute, Boston, MA, USA.
}

Guidelines for cervical cancer screening have evolved rapidly over the last several years, with a trend toward longer intervals between screenings and an increasing number of screening options, such as Pap/HPV co-testing and HPV testing as a primary screening. However, gynecological recommendations often do not include clinical considerations specific to patients on the female-to-male (FTM) spectrum. Both patients and providers may not accurately assess risk for HPV and other sexually transmitted infections, understand barriers to care, or be aware of recommendations for cervical cancer screening and other appropriate sexual and reproductive health services for this patient population. We review the evidence and provide guidance on minimizing emotional discomfort before, during, and after a pelvic exam, minimizing physical discomfort during the exam, and making adaptations to account for testosterone-induced anatomical changes common among FTM patients.

KEY WORDS: female-to-male; transgender; cervical cancer.

$\mathrm{J}$ Gen Intern Med 30(12): 1857-64

DOI: $10.1007 / \mathrm{s} 11606-015-3462-8$

(c) Society of General Internal Medicine 2015

\section{INTRODUCTION}

Previous publications have addressed performing "challenging pelvic exams"; ${ }^{1}$ however, little information has addressed how to improve pelvic examinations and cervical cancer screening for patients on the female-to-male (FTM) spectrum (Table 1), and providers lack knowledge of the psychosocial, physiological, and clinical concerns unique to this group. ${ }^{2}$ In a recent survey, only $29 \%$ of obstetrician-gynecologists felt comfortable caring for patients on the FTM spectrum, and $11 \%$ were unwilling to perform routine Pap tests on FTM patients. $^{2}$ Advances in screening for cervical cancer ${ }^{3-5}$ have reduced the frequency with which routine pelvic examinations are recommended for asymptomatic non-pregnant patients with female reproductive organs. ${ }^{6}$ Nevertheless, periodic pelvic examinations are indicated for cervical cancer screening ${ }^{3-5}$

Received January 12, 2015

Revised June 2, 2015

Accepted June 18, 2015

Published online July 10, 2015 in eligible transgender and cisgender patients regardless of symptoms, and are important in evaluating gynecological complaints.

In an effort to close these gaps, we present recommendations to guide cervical cancer screening for FTM patients based on a review of the literature and qualitative interviews with patients and clinicians experienced in providing care to this population. ${ }^{7,8}$ We conducted 32 one-on-one, in-depth interviews and an online survey $(n=86)$ with individuals on the FTM spectrum as well as three focus groups with 17 primary care physicians, gynecologists, physician assistants, and nurse practitioners. All study procedures were approved by the Fenway Health Institutional Review Board. We begin our discussion with two illustrative clinical examples; throughout the text, we also include representative quotes and corresponding gender identities and ages of some of the patients we interviewed in order to convey their lived experiences.

\section{CLINICAL EXAMPLES}

" $A$ " is a 22-year old patient who self-identifies as genderqueer and is relatively new to your practice. " $\mathrm{A}$ " has had sexual experiences only with partners whose assigned sex at birth was female, and has not engaged in any activities that involve penetration of their frontal pelvic opening. At "A's" last visit 2 weeks ago, they had their first Pap test. "A" does not experience strong dysphoria with their body and did not find the Pap experience to be emotionally difficult, but did experience extreme physical pain during the procedure. You just heard back from the lab that "A's" cytology sample is inadequate for interpretation. Given "A's" age, sexual history, and the pain they suffered during the Pap procedure, you wonder if you should just wait until next year before recommending retesting.

" $\mathrm{B}$ " is a 64-year-old patient who identifies as a trans man. "B" has been your patient for 20 years, but only transitioned a year ago. Before then, he identified as a woman. "B" has had many Pap tests in the past without experiencing distress; this will be his first since starting hormones. He notices genital changes he attributes to testosterone, and now feels anxious about having another pelvic exam. He asks, "Why do I have to do this now that I am a man?" and says his insurance no longer 
Table 1 Expanded definition of the term "female-to-male (FTM) spectrum"

"Female-to-male (FTM) spectrum" is a transgender umbrella term that refers to individuals assigned a female sex at birth whose gender identity or expression lies on a diverse spectrum of masculinity. Individuals may identify as men, transgender men, trans masculine, male, or another gender-nonconforming identity (e.g., genderqueer). In contradistinction, the term "cisgender women" refers to individuals assigned a female sex at birth who identify as women.

covers the procedure since he changed his gender marker to male. He seems upset, and you learn that he overheard two patients in the waiting room whispering about whether he was a man or a woman, and then the receptionist called him back by his birth name. Today's Pap would likely be his last before he ages out of screening, but he has a remote history of lowgrade squamous epithelial lesion with a negative colposcopy.

In each scenario, the patient is struggling with a number of barriers to screening, including physical discomfort, emotional and gender dysphoria-related discomfort, difficulties with insurance, a higher prevalence of inadequate tests among FTM patients, and/or feeling disrespected by others within the context of the medical visit. Challenges for the clinician include understanding the benefits and drawbacks to screening for an individual patient, and developing the skills to help the patient overcome these barriers and conduct the exam in a sensitive and technically proficient manner. These challenges highlight the need for specific clinical guidelines on how to accurately assess risk, prevent and/or minimize barriers, and promote regular screening among patients on the FTM spectrum.

\section{OVERVIEW OF KEY CLINICAL CONCERNS}

\author{
"There's so many different ways that the trans experience \\ can vary, and so many ways in which our relationships \\ with our bodies can vary. We're all individuals. We have \\ our own journey with our gender identity and with our \\ bodies, and we don't all have the same story." (Trans \\ male, age 49)
}

Individuals on the FTM spectrum are diverse in their gender identities and expressions. While not all such individuals desire cross-gender hormone therapy and/or surgery, these interventions are effective in alleviating gender dysphoria and are medically necessary for many. ${ }^{9,10}$ Common effects of testosterone include deepening voice, facial hair, redistribution of fat, and clitoral growth. "Top" surgery is the most common genderaffirming surgical procedure, and may include removal of the breast tissue and/or chest reconstruction. Some FTM patients may undergo either total or supracervical hysterectomy, usually without oophorectomy; patients do not always know which anatomical structures were removed during surgical procedures. ${ }^{11-15}$ Some FTM patients choose to have "lower" genital reconstructive surgery (e.g., metoidioplasty, phalloplasty); however, most do not. ${ }^{14,16,17}$

Both patients and providers in our interviews expressed misperceptions about HPV and cervical cancer risks (Table 2). FTM patients are at risk for sexually transmitted infections (STIs), including HPV, due to retention of the uterine cervix ${ }^{18}$ and sexual exposure ${ }^{15,19,20}$ in the majority of people in this population. Professional guidelines for routine cervical cancer and STI screenings in this population are identical to those recommended for cisgender women. ${ }^{21}$

Many FTM patients face barriers to receiving needed services due to a combination of factors, including stigma and discrimination, ${ }^{22,23}$ lack of insurance and access to genderaffirmative health care, ${ }^{24,25}$ patient and health care provider misperceptions pertaining to HPV and cervical cancer risk (Table 2), and apprehension about undergoing intrusive procedures such as pelvic examinations,${ }^{10}$ leading to decreased rates of cervical cancer screening compared to cisgender women. ${ }^{26}$ In addition, due partially to the atrophying effect of testosterone on the cervical epithelium, cervical cytology specimens are approximately ten times as likely to be unsatisfactory among patients on the FTM spectrum as among cisgender women. ${ }^{27}$

Consideration of psychosocial history is crucial when providing clinical care to FTM patients, many of whom have had negative experiences accessing health care. ${ }^{24,28} \mathrm{~A}$ gender minority stress model has been applied in order to understand the gender-related stressors faced by FTM people. ${ }^{29,30}$ Social stressors such as experiences of discrimination in the health care system (enacted stigma) lead to the expectation of negative experiences in health care (anticipated stigma). Expectations of poor care may delay routine preventive care such as cervical cancer screening.

Providers should be aware of the possibility of prior trauma among patients on the FTM spectrum, while remaining mindful that many develop resilience and healthy coping behaviors. This diversity of lived and health care experiences of FTM individuals underscores the need to treat each patient as an individual and to avoid assumptions. Maintaining a similar awareness of the diversity of sexual identity and sexual behavior among FTM patients reminds providers to ask openended questions about the gender of sex partners and sexual behaviors when taking a sexual history, to tailor contraception and safer-sex counseling accordingly, and to screen for cervical cancer according to protocols in all patients who retain a cervix (Table 2). It is imperative that cross-gender hormone therapy not be withheld or postponed because a patient on the FTM spectrum is not up to date with a Pap, just as one would not withhold needed services from a cisgender woman in this situation. ${ }^{31}$ 
Table 2 Common myths and facts about sexual behavior, sexual health risks, and appropriate screening for individuals on the FTM spectrum

\begin{tabular}{|c|c|c|}
\hline Topic & Myths & Facts \\
\hline $\begin{array}{l}\text { Sex partners/sexual behavior of } \\
\text { individuals on the FTM spectrum }\end{array}$ & $\begin{array}{l}\text { - Have few sex partners } \\
\text { - Never engage in any penetrative vaginal sex } \\
\text { practices } \\
\text { - Do not have sex with cisgender men and/or } \\
\text { engage in penis-in-vagina (PIV) sex }\end{array}$ & $\begin{array}{l}\text { - Have diverse sex partners across their lifetime (of any sexual } \\
\text { orientation and/or gender identity) } \\
\text { - Engage in a wide variety of sexual behaviors }\end{array}$ \\
\hline $\begin{array}{l}\text { Acquisition of HPV and other } \\
\text { sexually transmitted infections } \\
\text { (STIs) }\end{array}$ & $\begin{array}{l}\text { - Have minimal (or no) risk for acquiring HPV } \\
\text { and other STIs if no history of PIV sex }\end{array}$ & $\begin{array}{l}\text { - HPV and other STIs can be transmitted via all types of } \\
\text { sexual contact, including use of shared sex toys }\end{array}$ \\
\hline Screening for STIs & - Not necessary if no history of PIV sex & - Should be performed if there is any history of sexual contact \\
\hline $\begin{array}{l}\text { Prevention of unintended } \\
\text { pregnancy }\end{array}$ & $\begin{array}{l}\text { - Not a concern when having unprotected PIV sex } \\
\text { because testosterone treatment causes infertility }\end{array}$ & $\begin{array}{l}\text { - Contraception counseling is appropriate for premenopausal } \\
\text { individuals with natal female anatomy who are having PIV } \\
\text { sex }\end{array}$ \\
\hline Cervical cancer screening & $\begin{array}{l}\text { - Unnecessary if an individual who has not had } \\
\text { PIV sex finds Paps challenging } \\
\text { - Must be completed before cross-gender } \\
\text { hormone treatment can be initiated or } \\
\text { continued }\end{array}$ & $\begin{array}{l}\text { - Indicated for individuals with a history of any type of sexual } \\
\text { activity, and strategies exist to mitigate patient distress } \\
\text { - Cross-gender hormone treatment should be prescribed when } \\
\text { indicated and never be made contingent on having a Pap }\end{array}$ \\
\hline
\end{tabular}

\section{RECOMMENDATIONS FOR PROVIDERS ON HOW TO CONDUCT THE PELVIC EXAM}

\begin{abstract}
"It's very hard as a patient to give feedback to a doctor. Doctors are the boss...It is very hard for people to say to a doctor "Hey wait, this isn't how you should be doing this, this isn't comfortable for me." I think sometimes it's very hard for doctors to accept that too. And it's even harder when it's something that you're desperately uncomfortable with." (Male, age 27)
\end{abstract}

Given the inherent power dynamics between health care providers and patients, ${ }^{32}$ any encounter in which the locus of control is successfully shared provides an opportunity to develop resilience. ${ }^{33}$ Pre-existing trauma and discomfort induced when revealing natal genitalia discordant with gender identity may render the pelvic examination particularly challenging for FTM patients. Providers should therefore be attuned to the patient's needs, communicate respectfully, and ensure that each individual's sense of dignity, agency, and control is maintained.

\section{Before the Visit}

\begin{abstract}
"Are they trans-friendly and knowledgeable? Will I get weird looks?... It's uncomfortable for me as someone who does not identify as female to schedule an appointment that's typically seen to be a women's health issue." (Genderqueer, age 49)
\end{abstract}

Improving access to care begins before a transgender patient enters the office. Institutions can signal acceptance by participating in metrics such as the Healthcare Equality In$\operatorname{dex}^{34}$, posting inclusive nondiscrimination policies online, and indicating provider expertise in transgender health via the World Professional Association for Transgender Health (WPATH), Gay and Lesbian Medical Association (GLMA), or local institutional provider directories. The capacity of the electronic health record to document gender identity should be analyzed and updated, and registration and appointment scheduling procedures revised to include questions inclusive of all gender identities. ${ }^{35-37}$ Staff members who answer the phone should be trained to make no assumptions about gender identity from the timbre of a person's voice, the gender marker on their medical record, or their legal name.

\section{On Arrival at the Office}

\begin{abstract}
"It being an $O B / G Y N$ office, I was pretty much the only male sitting there...People think, why is he here?...I don't want to be outed. I don't want to be sitting there looked at like, "Who is this person?", (Male, age 53)
\end{abstract}

Patients who were interviewed described a variety of problems upon arrival at the office, related to staff insensitivity and waiting in a room full of cisgender women as a masculinepresenting individual. This effect is magnified if the patient's (still female-gendered) legal name is used in the waiting room and people express confusion when the (masculinepresenting) patient responds.

Office staff should be trained to expect patients with a wide variety of gender presentations, and to make no assumptions about any patient's gender identity based on appearance. Name and pronoun errors can be avoided by teaching reception staff to ask patients about their preferences at check-in ("What name and pronouns would you like us to use when addressing you or calling you into the exam room?"), and medical assistants and nursing staff can implement a systematic, non-gendered office procedure for summoning patients, such as using a patient's preferred name rather than an honorific plus their legal name (e.g., "John" or "Doe" rather than 
"Ms. Jane Doe"). In practices that cater exclusively to patients assigned a female sex at birth, FTM patients can be scheduled for the first or last visit of the day to minimize waiting time or can be taken to an exam room immediately after check-in.

Non-verbal indications such as poster and health brochure displays relevant only to cisgender female patients may suggest to FTM patients that the office is not inclusive or attuned to their unique health needs. Fortunately, many resources provide gender-inclusive and/or transgender-specific pamphlets relevant to gynecological care, such as: tobacco cessation, ${ }^{38}$ partner abuse, $^{39}$ HPV infection, ${ }^{40}$ cervical cancer screening, ${ }^{41}$ safer sex, ${ }^{42}$ and HIV prevention. ${ }^{43}$ Finally, an FTM patient's sense of safety can be threatened if the practice offers only gendered restrooms where their gender may be explicitly challenged. Single-stall restrooms can easily be converted from gendered to gender-neutral by changing signage.

\section{Patient-Provider Communication Before the Exam}

\section{"Let folks know what their options are, affirm them that they are not the only ones who feel this way, ask them about preferred gender pronouns, ask them about how they want their parts to be referred to ... let them know if it's uncomfortable at any point that they can stop. Let folks know if they do stop in the middle of the Pap, what their options are." (Trans masculine, age 29)}

The formation of a trusting relationship between a provider and patient on the FTM spectrum requires sensitivity and respect. Providers should re-query each new patient regarding preferred name and pronouns, and use the patient's choices throughout the encounter. Since some FTM patients may be uncomfortable with the use of gendered terminology during the history or examination, it is important to ask what anatomical terms they prefer. In addition, words with violent and/or sexual connotations should be avoided (Tables 3 and 4).
Prompt recognition of and apology for any communication breaches are paramount.

Many patients reported that the Pap test triggers gender dysphoria, due to traditional views of the procedure as part of a "woman's wellness visit" and having another person view body parts discordant with the patient's gender identity. When discussing reasons for screening, providers should emphasize the ubiquity of HPV infection and offer gender-neutral explanations by explaining that infection of any mucosal surface - throat, genitals, and anus - can cause cancer. Moreover, the Pap test should be presented as a non-gendered cancer screening procedure rather than a screen for cancer of female reproductive organs.

New patients should be offered a review of what to expect during the procedure, to the extent preferred by each individual. Useful questions include: "Have you had a pelvic examination/Pap test before?" "Would you like me to explain the details of the procedure?" "How have your past experiences gone?" "Is there anything that would make you more comfortable?" The provider can then provide tailored information about the exam, ascertain patient preferences regarding provider gender and chaperone, and review options that may facilitate emotional and physical comfort (Table 5). Several patients preferred to have a partner or friend with them during the exam, and viewed a chaperone from the health care practice as a voyeur. Individual preferences should be respected whenever possible.

Several patients and providers suggested benzodiazepines or even conscious sedation for patients with severe anxiety. While use of sedative-hypnotics can be helpful, this practice requires careful consideration when patients have a trauma history, as these agents increase the likelihood of dissociation, may reduce a patient's sense of control, and can interfere with the memory of what actually transpires during an exam, thereby potentially re-traumatizing the patient. ${ }^{1,44}$ Therefore, although antianxiety medication may be an important tool for some patients in overcoming barriers to being examined, informed consent should be obtained before using

Table 3 Gender-neutral language for use during pelvic examinations

\begin{tabular}{lll}
\hline \hline Gendered & Less gendered & Least gendered \\
\hline Vulva & & External pelvic area \\
Oabia & & Outer parts \\
Vagina & & Outer folds \\
Uterus, ovaries & Reproductive organs & Genital opening, frontal pelvic opening, internal canal \\
& & Internal organs \\
Breasts & Pap test & Chest parts \\
Pap smear & Cervical cancer & Cancer screening \\
Bra/panties & & Cancer, HPV-related cancer \\
Pads/tampons & & Underwear \\
Period/menstruation & & Any absorbent product that works for the patient \\
(e.g., Depends) & Bleeding \\
\hline
\end{tabular}


Table 4 Examples of non-violent, non-sexualized language for use during pelvic examinations

\begin{tabular}{lc}
\hline \hline Negative connotation (violent or sexual) & Neutral/positive connotation \\
\hline $\begin{array}{l}\text { Stirrups } \\
\text { Avoid unnecessary touching of the patient and phrases such as "Scoot down until your } \\
\text { bottom touches my hand" }\end{array}$ & Footrests \\
"Open your legs" patient to move to the end of the table & "Let your legs drop to either side" \\
$\begin{array}{l}\text { To describe the labia: "Lips" } \\
\text { "Blades of the speculum" }\end{array}$ & "Outer folds" Acceptable: "Bills of the speculum" \\
$\begin{array}{l}\text { To describe sensation of speculum insertion or cervical sample collection: } \\
\text { "I'm going to come into you now" }\end{array}$ & $\begin{array}{l}\text { Preferred: "Opening the speculum" without specifying going to insert the speculum now" "You may feel a } \\
\text { "You're going to feel a little poke [prick]" }\end{array}$ \\
\hline
\end{tabular}

sedatives, and the exam should be conducted in the presence of a patient-approved chaperone.

Since minor bleeding is common after cytology sampling, but can be an unpleasant reminder of menstruation or prior trauma for some patients, mention and normalize this possibility using non-gendered language (Table 3). In addition, because FTM patients are more likely to have unsatisfactory Pap results, ${ }^{27}$ yet more likely to delay returning for repeated testing, ${ }^{26}$ providers should prepare patients for the possible need to repeat a
Pap and follow official guidelines that recommend retesting within 2-4 months of an initial inadequate test.

During all of these discussions about the pelvic exam, providers should consistently emphasize that the locus of control will reside with the patient - that is, it will be up to the patient to decide if and when to undergo the procedure and whether or not to continue or halt the exam. In order to ensure that the pelvic exam is stopped immediately if necessary, providers and patients should agree in advance how this decision will be communicated.

Table 5 Strategies to facilitate pelvic examination and optimize cervical cancer screening for FTM patients

\begin{tabular}{|c|c|}
\hline Before the visit & $\begin{array}{l}\text { - Non-discrimination policy on ads and website } \\
\text { - Providers listed in WPATH/GLMA directories } \\
\text { - Trained staff communicate sensitively when scheduling appointments } \\
\text { - Trans-inclusive options on registration forms } \\
\text { - Gender identity, preferred name, and pronouns documented in electronic health record }\end{array}$ \\
\hline On arrival at the office & $\begin{array}{l}\text { - Schedule as first or last appointment, or room patient quickly after check-in } \\
\text { - Presence of brochures, magazines, and posters that are non-gendered and relevant for } \\
\text { and/or feature individuals on the FTM spectrum } \\
\text { - Non-gendered restroom available }\end{array}$ \\
\hline Before the exam & $\begin{array}{l}\text { - Ask patient for preferred pronouns and anatomical terms } \\
\text { - Take a respectful and adequate sexual history } \\
\text { - Apologize immediately for any communication missteps } \\
\text { - Offer to review mechanics of the exam with all new patients } \\
\text { - Ask patients about prior pelvic exam experiences and assess comfort level and barriers } \\
\text { - Discuss options to optimize locus of control (e.g., permit patient to undress only from the } \\
\text { waist down, self-insert the speculum, dispense with footrests and/or dorsal lithotomy positioning, } \\
\text { discuss how to signal distress or stop the exam) } \\
\text { - Discuss exam techniques that will be used to optimize physical comfort (see below) } \\
\text { - Consider offering anxiety medication, with caution } \\
\text { - Consider suggesting short-course low-dose topical estrogen for patients with past } \\
\text { unsatisfactory cytology results } \\
\text { - Respect patient preferences regarding provider gender and presence, identity, and gender } \\
\text { of a chaperone } \\
\text { - Allow patient to decide if and when to proceed with or stop the exam }\end{array}$ \\
\hline During the exam & $\begin{array}{l}\text { - Use patient's preferred name, pronouns, and anatomical terms throughout the encounter } \\
\text { - Avoid comments about body or genital changes } \\
\text { - Use a small speculum, with water-based lubricant and/or topical lidocaine applied to the introitus } \\
\text { before speculum insertion } \\
\text { - Swab a greater circumference of the cervix than typical and use multiple collection instruments } \\
\text { to optimize collection of an adequate sample } \\
\text { - Collect samples for cytology and HPV co-testing for all patients aged } 30-65 \text { whenever possible } \\
\text { - Consider collecting a vaginal swab for primary HPV screening if speculum examination is not possible }\end{array}$ \\
\hline After the exam & $\begin{array}{l}\text { - Warn about bleeding and offer absorbent products using non-gendered language } \\
\text { - If results are inadequate, use the same } 2 \text {-4-month guideline for retesting as with cisgender patients } \\
\text { - Indicate testosterone use on the cytology requisition } \\
\text { - Be prepared to advocate for patient with insurance company if denied coverage } \\
\text { - Check that patients who experience distress or discomfort have a post-exam self-care plan in place } \\
\text { - Ensure preferred name and pronouns are used when communicating results/performing outreach }\end{array}$ \\
\hline
\end{tabular}




\section{Performance of the Speculum Exam and Cervical Sampling}

\begin{abstract}
"Ask people if they want to insert the speculums themselves, give them agency and control over what's happening. Ask them whether they would prefer to be distracted or whether they'd prefer that you get it done with minimum fuss. Allow for the fact that everyone's emotional, interpersonal needs are different and try and work with that." (Male, age 34)
\end{abstract}

Once a patient chooses to proceed, it is important to continue to use non-gendered language while conducting the exam (Table 3) and to use the anatomical terminology that the patient has indicated they prefer. Refrain from making comments about physical or genital changes (e.g., appearance of the chest after "top" surgery or clitoral enlargement) observed during the exam. These comments can make the patient feel that their body is viewed as aberrant or an object of curiosity. Whatever options a patient requests in order to maintain a sense of control should be followed during the exam; these include undressing only from the waist down, dispensing with stirrups and/or the dorsal lithotomy position, and patient self-insertion of the speculum or permitting insertion by a partner or trusted friend ${ }^{1}$ (Table 5).

In addition to causing cervical epithelial atrophy, ${ }^{26}$ testosterone treatment can induce vaginal epithelial atrophy ${ }^{45}$ that may make passage of a speculum uncomfortable. Strategies to mitigate discomfort include the use of a pediatric or long, narrow speculum, application of a small amount of lubricant to the speculum, and application of topical lidocaine to the vaginal introitus ${ }^{1}$ (Table 5). Noncarbomer-containing, water-based lubricant does not affect the adequacy of liquid-based cytology specimens or ascertainment of gonorrhea and chlamydia infection. ${ }^{46-49}$

Provider-suggested techniques to optimize cervical sampling included swabbing a wide circumference of the cervix and using multiple sampling tools. Such purposeful sampling must be balanced by close attention to patient comfort during the procedure. Several providers suggested that application of low-dose vaginal estrogen for five nights prior to the exam might reduce cervical atrophy among FTM patients receiving testosterone, as this strategy has been found to improve specimen adequacy among postmenopausal cisgender patients. ${ }^{45}$ Some patients on the FTM spectrum may be averse to the idea of increasing the amount of estrogen in their bodies even in the short term. Providers therefore may wish to reserve discussion of vaginal estrogen for patients for whom they previously have been unable to obtain an adequate sample. Testosterone use should be documented on the cytology requisition, as diligent cytological interpretation has been shown to improve diagnostic accuracy among patients with atrophic cervicovaginal specimens. ${ }^{50}$
Almost all FTM patients interviewed expressed a strong preference for primary HPV screening via vaginal swab as opposed to screening involving a speculum exam and Pap test. Data detailing performance characteristics of primary HPV screening among patients on the FTM spectrum are needed in order to establish the effectiveness and safety of this approach. Moreover, the accuracy of HPV testing on patient-collected versus provider-collected samples has yet to be established; ${ }^{51}$ it is currently recommended that primary HPV testing be accomplished via cervical sampling during a speculum exam. ${ }^{52}$ However, for FTM patients who decline a speculum exam, a vaginal swab for HPV may represent an acceptable screening alternative. Both cytology and HPV testing miss some cancer cases, ${ }^{53}$ and most cervical cancer occurs in individuals who have not recently been tested; therefore, screening strategies should focus on increasing population coverage and minimizing loss to follow-up.

There is no evidence to support performance of routine pelvic examinations in asymptomatic nonpregnant cisgender women for reasons other than periodic cervical cancer screening; ${ }^{6}$ these guidelines should also be followed for patients on the FTM spectrum.

\section{After the Exam}

"I was surprised and alarmed when I got a bill... Maybe do that stage of the research ahead of time so that you can give an informed answer of whether or not [the exam will be covered]. Or at least know how to help the patient navigate the insurance." (Male, age 27)

The manner in which the pelvic exam encounter is concluded is just as important as how it is introduced. Alert patients to the possibility of cervical bleeding, and offer absorbent products using non-gendered language (Table 3 ). Permit patients to dress before conversing about findings to help maintain dignity and control, and begin with positive statements such as "I'm glad we were able to complete the exam today" and "This screening was important for your health." Providers should help patients with a history of trauma or who appear distressed during the exam to develop a self-care plan to follow after leaving the office.

The positive experience of a successful exam for patients can be eclipsed by the subsequent receipt of results using the wrong name or inappropriate-gendered language; therefore, provider attention to consistency across all forms of communication is paramount. Similarly, the screening experience may be complicated by denial of insurance coverage for Pap or HPV tests among FTM patients if they have a male gender marker; therefore, providers should be prepared to advocate for coverage. 


\section{CONCLUSIONS}

In summary, patients on the FTM spectrum are at risk for HPV and other STIs, and face unique barriers to adequate cervical cancer screening and other medically necessary sexual and reproductive health services. When indicated, providers and other health care personnel can take steps to facilitate comfortable, safe, and technically successful pelvic examinations for FTM patients. Key communication recommendations include asking and using each patient's preferred name, pronouns, and anatomical terms; taking an adequate sexual history and providing relevant sexual health counseling; describing cervical cancer screening as a non-gendered cancer screening procedure; explaining the mechanics of speculum examination/Pap testing to the extent preferred by each individual; and reviewing and utilizing methods elected by the patient to minimize emotional and physical discomfort and maintain their locus of control throughout the encounter.

Acknowledgments: The authors would like to thank the Harvard Medical Student Center for Primary Care and the Open Gate Foundation for their generous support of this project.

M. Agénor is supported by National Cancer Institute Cancer Education Program grant 3R25CA057711. The contents of this paper are the sole responsibility of the authors and do not necessarily reflect the views of the National Institutes of Health.

Conflicts of Interest: The authors declare that they do not have a conflict of interest.

Corresponding Author: Jennifer Potter, MD; The Fenway Institute Fenway Health, Boston, MA, USA (e-mail:jpotter@bidmc.harvard.edu).

\section{REFERENCES}

1. Bates CK, Carroll N, Potter J. The challenging pelvic examination. J Gen Intern Med. 2011;26(6):651-657.

2. Unger CA. Care of the transgender patient: a survey of gynecologists' current knowledge and practice. J Womens Health (Larchmt). Epub 2014 Dec 19.

3. American College of Obstetricians and Gynecologists Practice Bulletin Number 131: screening for cervical cancer. Obstet Gynecol. 2012;120(5): 1222-1238.

4. Moyer VA. Screening for cervical cancer: US Preventive Services Task Force recommendation statement. Ann Intern Med. 2012;156(12):880-891.

5. Saslow D, Solomon D, Lawson HW, Killackey M, Kulasingam SL, Cain J, et al. American Cancer Society, American Society for Colposcopy and Cervical Pathology, and American Society for Clinical Pathology screening guidelines for the prevention and early detection of cervical cancer. CA Cancer J Clin. 2012;62(3): 147-172.

6. Gaseem A, Humphrey LL, Harris R, Starkey M, Denberg TD. Screening pelvic examination in adult women: a clinical practice guideline from the American College of Physicians. Ann Intern Med. 2014;161(1):67-72.

7. Peitzmeier SM, Agenor M, Bernstein I, Alizaga N, McDowell M, Reisner SL, et al. Barriers and facilitators to cervical cancer screening among femaleto-male patients. In preparation.

8. Bernstein I, Potter J, Peitzmeier SM. If you have it, check it: overcoming barriers to cervical cancer screening with patients on the female-to-male transgender spectrum. Gay and Lesbian Medical Association; 2014; Baltimore, MD.

9. Smith YL, Van Goozen SH, Kuiper AJ, Cohen-Kettenis PT. Sex reassignment: outcomes and predictors of treatment for adolescent and adult transsexuals. Psychol Med. 2005;35(01):89-99.

10. Coleman E, Bockting W, Botzer M, Cohen-Kettenis P, DeCuypere G, Feldman J, et al. Standards of care for the health of transsexual, transgender, and gender-nonconforming people, version 7 . Int $\mathrm{J}$ Transgend. 2012;13(4): 165-232.

11. Driak D, Samudovsky M. Could a man be affected with carcinoma of cervix?-The first case of cervical carcinoma in trans-sexual person (FtM)case report. Acta Med (Hradec Kralove). 2005;48(1):53-55.

12. Kaufman R. Introduction to transgender identity and health. In: Makadon H, Mayer K, Potter J, Goldhammer H, eds. Fenway Guide to Lesbian, Gay, Bisexual and Transgender Health. Philadelphia: American College of Physicians; 2008:331-363.

13. van Trotsenburg MA. Gynecological aspects of transgender healthcare. Int J Transgend. 2009;11(4):238-246.

14. Feldman J. Medical and surgical managment of the transgender patient: What the primary care clinician needs to know. In: Makadon H, Mayer K, Potter J, Goldhammer H, eds. Fenway Guide to Lesbian, Gay, Bisexual, and Transgender Health. Philadelphia: American College of Physicians; 2008:365-392.

15. Bauer GR, Travers R, Scanlon K, Coleman TA. High heterogeneity of HIVrelated sexual risk among transgender people in Ontario, Canada: a province-wide respondent-driven sampling survey. BMC Public Health. 2012;12(1):292.

16. O'Hanlan KA, Dibble SL, Young-Spint M. Total laparoscopic hysterectomy for female-to-male transsexuals. Obstet Gynecol. 2007;110(5):1096-1101.

17. Kenagy GP. Transgender health: findings from two needs assessment studies in Philadelphia. Health Soc Work. 2005;30(1):19-26.

18. Grant JM, Mottet LA, Tanis J, Herman J, Harrison J, Keisling M. National Transgender Discrimination Survey Report on Health and Health Care. Washington, DC: National Center for Transgender Equality and National Gay and Lesbian Task Force; 2010.

19. Bauer GR, Redman N, Bradley K, Scheim AI. Sexual health of trans men who are gay, bisexual, or who have sex with men: results from Ontario, Canada. Int J Transgend. 2013;14(2):66-74.

20. Reisner SL, White JM, Mayer KH, Mimiaga MJ. Sexual risk behaviors and psychosocial health concerns of female-to-male transgender men screening for STDs at an urban community health center. AIDS Care. 2014;26(7):857-864.

21. American College of Obstetricians and Gynecologists. Committee Opinion: Health Care for Transgender Individuals. Obstet Gynecol. 2011;118(6): 1454.

22. Poteat T, German D, Kerrigan D. Managing uncertainty: a grounded theory of stigma in transgender health care encounters. Soc Sci Med. 2013;84:22-29.

23. Reisner SL, Gamarel KE, Dunham E, Hopwood R, Hwahng S. Female-tomale Transmasculine adult health a mixed-methods community-based needs assessment. J Am Psychiatr Nurses Assoc. 2013;19(5):293-303.

24. Grant JM, Mottet L, Tanis JE, Harrison J, Herman J, Keisling M. Injustice at every turn: A report of the national transgender discrimination survey. Washington, DC: National Center for Transgender Equality; 2011.

25. Snelgrove JW, Jasudavisius AM, Rowe BW, Head EM, Bauer GR. "Completely out-at-sea" with "two-gender medicine": a qualitative analysis of physician-side barriers to providing healthcare for transgender patients. BMC Health Serv Res. 2012;12(1):110.

26. Peitzmeier SM, Khullar K, Reisner SL, Potter J. Pap test use is lower among female-to-male patients than non-transgender women. Am J Prev Med. 2014;47(6):808-812.

27. Peitzmeier SM, Reisner SL, Harigopal P, Potter J. Female-to-male patients have high prevalence of unsatisfactory Paps compared to nontransgender females: implications for cervical cancer screening. J Gen Intern Med. 2014;29(5):778-784.

28. Cruz TM. Assessing access to care for transgender and gender nonconforming people: a consideration of diversity in combating discrimination. Soc Sci Med. 2014;110:65-73.

29. Hendricks ML, Testa RJ. A conceptual framework for clinical work with transgender and gender nonconforming clients: an adaptation of the Minority Stress Model. Prof Psychol Res Pr. 2012;43(5):460.

30. Reisner SL, Pardo ST, Gamarel KE, White JM, Pardee DJ, Meier SC. Trans masculine experiences of stigma in U.S. healthcare: a gender minority stress model of substance use to cope with mistreatment. LGBT Health. Forthcoming 2015.

31. Stewart FH, Harper CC, Ellertson CE, Grimes DA, Sawaya GF, Trussell J. Clinical breast and pelvic examination requirements for hormonal contraception: current practice vs evidence. JAMA. 2001;285(17):22322239.

32. Goodyear-Smith F, Buetow S. Power issues in the doctor-patient relationship. Health Care Anal. 2001;9(4):449-462.

33. Eckstrand K, Sciolla A, Potter J. Trauma and resilience in the lives of people who are LGBT, gender nonconforming, and born with DSD: 
Implications for Clinical Care and Health Outcomes. In: Hollenbach $\mathrm{AD}$, Eckstrand KL, Dreger A, eds. Implementing Curricular and Institutional Climate Changes to Improve Health Care for Individuals Who are LGBT, Gender Nonconforming, or Born with DSD. Association of American Medical Colleges; 2014: 32-39. http://lgbt.ucsf.edu/sites/lgbt.ucsf.edu/ files/wysiwyg/AAMC_LGBT-DSD\%20Report\%202014.pdf. Accessed June 16, 2015.

34. Human Rights Campaign. Healthcare Equality Index. 2014. http://www. hrc.org/hei. Accessed June 16, 2015.

35. Callahan EJ, Sitkin N, Ton H, Eidson-Ton WS, Weckstein J, Latimore D. Introducing sexual orientation and gender identity into the electronic health record: One Academic Health Center's Experience. Acad Med. Epub 2014 Aug 26.

36. GenIUSS Group. Best practices for Asking Questions to Identify Transgender and Other Gender Minority Respondents on Population-Based Surveys. http://williamsinstitute.law.ucla.edu/wp-content/uploads/geniussreport-sep-2014.pdf: Williams Institute. 2014. Accessed June 16, 2015.

37. Cahill S, Singal R, Grasso C, King D, Mayer K, Baker K, et al. Do Ask, Do Tell: high levels of acceptability by patients of routine collection of sexual orientation and gender identity data in four diverse American Community Health Centers. PLoS ONE. 2014;9(9):e107104.

38. American Cancer Society. Tobacco and the GLBT community. http://www. lgbttobacco.org/files/TObacco\%20and\%20the\%20LGBT\%20Community. pdf. 2003. Accessed June 16, 2015.

39. The Network/La Red. Partner Abuse Happens to Trans Folks Too! http:// tnlr.org/wp-content/uploads/2011/04/trans-partner-abuse-handout.pdf. Accessed June 18, 2015.

40. Fenway Health. HPV. http://fenwayfocus.org/wp-content/uploads/2015/ 06/12.198_HPVbrochure_v3_pages.pdf. Accessed June 16, 2015.

41. Fenway Health. I'm on the FTM spectrum: What do I need to know about HPV and cancer? http://fenwayfocus.org/wp-content/uploads/2015/06/ com166_hpv_cancer-digital2.pdf. Accessed June 16, 2015.

42. Müller A, Gender DynamiX: Sexual Health for Transgender \& Gender NonConforming People. http://www.genderdynamix.org.za/wp-content/uploads/2013/05/GDX-Safer-Sex-Bklt-Eng.pdf. Accessed June 16, 2015.

43. The Fenway Institute. Protecting yourself from HIV through pre-exposure prophylaxis: What you need to know. http://www.lgbthealtheducation.
org/wp-content/uploads/12.125_PrEPdocuments_consumers_cover_v3. pdf. Accessed June 16, 2015.

44. Badura AS, Reiter RC, Altmaier EM, Rhomberg A, Elas D. Dissociation, somatization, substance abuse, and coping in women with chronic pelvic pain. Obstet Gynecol. 1997;90(3):405-410.

45. Baldassarre M, Giannone F, Foschini M, Battaglia C, Busacchi $\mathbf{P}$, Venturoli S, et al. Effects of long-term high dose testosterone administration on vaginal epithelium structure and estrogen receptor- $\alpha$ and- $\beta$ expression of young women. Int J Impot Res. 2013;25(5):172-177.

46. Amies A-ME, Miller L, Lee S-K, Koutsky L. The effect of vaginal speculum lubrication on the rate of unsatisfactory cervical cytology diagnosis. Obstet Gynecol. 2002;100(5, Part 1):889-892.

47. Brady K, Sizemore $\mathbf{K}$, Duff $\mathbf{P}$, Aamodt L. The effect of bacteriostatic lubricant on group B streptococcal cultures of the female genital tract. Obstet Gynecol. 1989;74(6):848-850.

48. Griffith WF, Stuart GS, Gluck KL, Heartwell SF. Vaginal speculum lubrication and its effects on cervical cytology and microbiology. Contraception. 2005;72(1):60-64.

49. Harer WB Jr, Valenzuela G, Lebo D. Lubrication of the vaginal introitus and speculum does not affect Papanicolaou smears. Obstet Gynecol. 2002;100(5, Part 1):887-888.

50. Acs G, Gupta PK, Baloch ZW. Glandular and squamous atypia and intraepithelial lesions in atrophic cervicovaginal smears. Acta Cytol. 2011;44(4):611-617.

51. Arbyn M, Verdoodt F, Snijders PJ, Verhoef VM, Suonio E, Dillner L, et al. Accuracy of human papillomavirus testing on self-collected versus clinician-collected samples: a meta-analysis. Lancet Oncol. 2014;15(2):172-183.

52. Cox JT, Castle PE, Behrens CM, Sharma A, Wright Jr TC, Cuzick J. Comparison of cervical cancer screening strategies incorporating different combinations of cytology, HPV testing, and genotyping for HPV 16/18: results from the ATHENA HPV study. Am J Obstet Gynecol. 2013;208(3): 184.e181-184.e111.

53. Zhao C, Li Z, Nayar R, Levi AW, Winkler BA, Moriarty AT, et al. Prior HighRisk Human Papillomavirus Testing and Papanicolaou Test Results of 70 Invasive Cervical Carcinomas Diagnosed in 2012: Results of a Retrospective Multicenter Study. Arch Pathol Lab Med. Epub 2014 Apr 2. 